\title{
The relationship between IL-6 and thrombocytosis accompanying gastrointestinal tumours
}

\author{
Valéria Jósa ${ }^{1}$, Valentin Brodszky², Attila Zaránd ${ }^{3}$, Tünde Mezei ${ }^{4}$, Zsuzsanna Szilasi ${ }^{5}$, Keresztély Merkel ${ }^{6}$, \\ Adrienne Fehér ${ }^{7}$, Zoltán Szállási ${ }^{8}$, Zsolt Baranyai ${ }^{3}$ \\ ${ }^{1}$ Department of Otorhinolaryngology and Head and Neck Surgery, Flór Ferenc Hospital, Kistarcsa, Hungary \\ ${ }^{2}$ Department of Health Economics, Corvinus University of Budapest, Budapest, Hungary \\ ${ }^{3} 1^{\text {st }}$ Department of Surgery, Semmelweis University Budapest, Budapest, Hungary \\ ${ }^{4}$ Department of Urology, Jahn Ferenc, Budapest, Hungary \\ ${ }^{5}$ Department of Otorhinolaryngology and Head and Neck Surgery, HDF Medical Centre, Budapest, Hungary \\ ${ }^{6}$ Department of Surgery, Szent Imre Hospital, Budapest, Hungary \\ ${ }^{7}$ Department of Laboratory Medicine, Faculty of Medicine, Semmelweis University, Budapest, Hungary \\ ${ }^{8}$ Computational Health Informatics Program (CHIP), Harvard Medical School, Boston, USA
}

Gastroenterology Rev 2020; 15 (3): 215-219

DOI: https://doi.org/10.5114/pg.2020.98538

Key words: thrombocytosis, IL-6, gastrointestinal tumours, paraneoplastic pathway.

Address for correspondence: Zsolt Baranyai MD, PhD, $1^{\text {st }}$ Department of Surgery, Semmelweis University Budapest, Hungary,

phone: +36 30/4500-388, e-mail: barazso@gmail.com

\begin{abstract}
Introduction: Several reports have stated that thrombocytosis is associated with worse survival and higher rate of metastasis in solid tumours. A study in ovarian tumours implicated IL-6 produced by tumour cells as a key mechanistic factor.

Aim: To evaluate the relevance of this paraneoplastic pathway in gastrointestinal cancer.

Material and methods: After excluding thromboembolic and inflammatory disorders, 161 patients were enrolled who had been operated due to various gastrointestinal cancer at the $1^{\text {st }}$ Department of Surgery at the Semmelweis University between 2015 and 2017. Platelet counts and serum IL-6 levels were determined from preoperative blood samples. Thrombocytosis was defined as the upper limit of normal platelet count, e.g. $400 \times 10^{3} / \mu$ l.

Results: A weak but significantly positive correlation was found between elevated platelet counts and serum IL-6 (correlation coefficient: $R=0.214, p=0.006)$, which became more pronounced in colon and oesophageal cancer if evaluated in the different tumour types ( $R=0.292$ and $R=0.419$, respectively). However, using a multivariant linear regression model $\left(R^{2}=0.47\right)$ corrected with haemoglobin, white blood cell count, and advanced disease stage, the analysis showed no significant correlation between serum IL-6 and platelet counts.

Conclusions: In gastrointestinal cancer our study did not support the paracrine-mediated paraneoplastic pathway described in ovarian tumors. Thrombocytosis showed significant correlation with white blood cells instead of serum IL-6, which implies that the inflammatory process may influence both parameters. Further studies are needed on larger patient cohorts.
\end{abstract}

\section{Introduction}

In recent decades several authors have reported that thrombocytosis was associated with higher incidence of metastases and worse prognosis in gastrointestinal tumours [1, 2]. Numerous studies have shown an association between platelets and tumours. In animal studies correlation was found between platelet inhibition [3] or depletion [4] and decreased metastasis formation. In thrombocyte-depleted animals the infusion of platelet concentrate restored the metastasising potential of tu- mour cells administered intravenously [5]. It is assumed that a certain mechanistic link exists between tumour cells and platelets. The thrombocytes often adhere to tumour cells [6]. On the one hand, platelets protect them from mechanical insults, and on the other hand, platelets interfere with the cell-mediated immune response: they present large amount of MHC-I antigen on their surface, and the recognition of tumour cells is compromised by the immune system because the platelets covering the tumour cells imply normal phenotype of the host [7]. Despite numerous studies, the exact 
Table I. Clinicopathological data

\begin{tabular}{|c|c|c|c|c|c|c|c|c|c|}
\hline \multirow[t]{2}{*}{ Organ } & \multirow[t]{2}{*}{$N$} & \multirow[t]{2}{*}{ Male/female } & \multicolumn{4}{|c|}{ Stage } & \multirow{2}{*}{$\begin{array}{l}\text { Mean PLT } \\
{\left[\times 10^{3} / \mu \mathrm{l}\right]}\end{array}$} & \multirow{2}{*}{$\begin{array}{c}\text { Mean IL-6 } \\
\text { [pg/ml] }\end{array}$} & \multirow{2}{*}{$\begin{array}{l}\text { PLT } \times \text { IL-6 } \\
\text { correlation }\end{array}$} \\
\hline & & & 1 & 2 & 3 & 4 & & & \\
\hline Oesophagus & 14 & $14 / 0$ & 0 & 4 & 4 & 6 & 250.52 & 8.90 & 0.419 \\
\hline Primary liver* & 10 & $6 / 4$ & 2 & 2 & 4 & 2 & 170.20 & 5.29 & 0.153 \\
\hline Stomach & 35 & $27 / 8$ & 3 & 6 & 6 & 20 & 291.49 & 12.78 & 0.197 \\
\hline Pancreas & 36 & $21 / 15$ & 4 & 10 & 12 & 10 & 324.67 & 13.13 & 0.175 \\
\hline Colon & 33 & $17 / 16$ & 3 & 9 & 12 & 9 & 340.36 & 12.91 & 0.292 \\
\hline Rectum & 29 & $20 / 9$ & 5 & 6 & 12 & 6 & 311.41 & 10.85 & -0.006 \\
\hline
\end{tabular}

*Barcelona criteria. $1=A, 2=B, 3=C, 4=D$.

pathomechanism of the relationship between thrombocytosis and tumours is not clear. Stone et al. found significant correlation not only between elevated platelet counts and thrombopoietin (TPO), but also with serum interleukin-6 (IL-6) in patients with ovarian cancer [8]. Based on those results, they suggested a possible paracrine-mediated paraneoplastic pathway: the IL-6 expressed and secreted by the ovarian tumour induces TPO synthesis in the liver, which stimulates the bone marrow and increases the platelet count. The end-result of this process is tumour-induced thrombocytosis. This pathway has not been studied in other tumours.

\section{Aim}

Our aim was to uncover any correlation between thrombocytosis and serum IL-6 in gastrointestinal tumours.

\section{Material and methods}

Between March 2015 and March 2017, 192 patients with different gastrointestinal tumours undergoing sur-

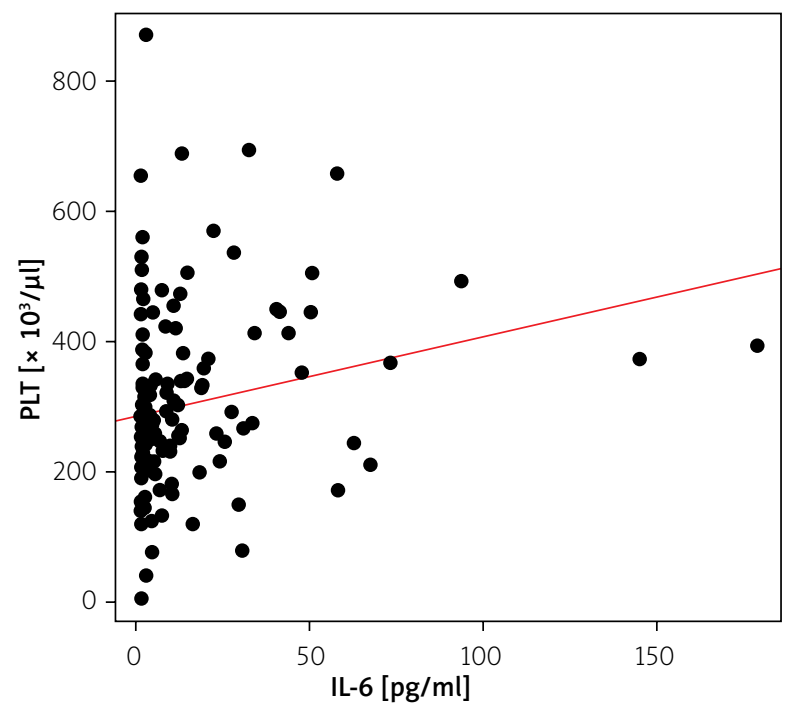

Figure 1. Correlation between elevated platelet counts and serum IL-6 gical intervention were evaluated in the $1^{\text {st }}$ Department of Surgery of Semmelweis University. Exclusion criteria were any inflammatory disease (pneumonia, wound complication, abscess, cholecystitis, inflammation of the intravenous line, endocarditis, urological infection, Crohn's disease, ulcerative colitis), thromboembolic complications (deep vein thrombosis, pulmonary embolism, heart attack), and corticosteroid therapy. A total of 31 patients were excluded. Platelet count and IL-6 level were defined from blood samples drawn routinely before the operation (within 4 weeks). Thrombocytosis was defined as a platelet count exceeding $400 \times 10^{3} / \mu$ l. Serum IL- 6 was measured with an ADVIA 2120 Hematology Analyzer.

\section{Statistical analysis}

Multivariate linear regression was applied to determine predictors of the platelet count. The coefficient and its 95\% confidence interval $(\mathrm{Cl})$ were calculated for each variable. Pairwise associations between scale variables were analysed by Pearson correlation. All the statistical tests were two-sided, and $p<0.05$ was considered statistically significant. Data were analysed by using RStudio program package (Version 1.0.143 - ${ }^{\circ}$ 2009-2016 RStudio, Inc.).

\section{Results}

In the examined time interval patients undergoing surgery had a wide spectrum of gastrointestinal tumours regarding localisation and disease stage. We evaluated the correlation of platelet counts and serum IL-6 in each tumour type (Table I). Because the number of patients was relatively small in the subgroups, none of the correlations proved to be significant. However, a moderately strong positive correlation could be found in colon and oesophageal cancer.

We found weak but significantly positive correlation between elevated platelet counts and serum IL-6 (correlation coefficient: $R=0.214, p=0.006$ ) (Figure 1 ). 
Tumour grade did not show a significant effect on platelet counts and IL-6 level. However, if patients were divided in two groups according to disease stage defined as early (stage 1 and 2) or advanced disease (stage 3 and 4) - IL-6 was significantly higher in the latter group (Table II).

Multivariant analysis corrected for haemoglobin, white blood cell counts, and advanced stages showed no significant correlation between IL- 6 and thrombocytosis (Table III).

Haemoglobin showed negative, while white blood cell counts showed positive significant association with the platelet counts. A total of 12 patients had a history of thromboembolic event. We found lower platelet counts in patients with positive thromboembolic history $\left(251\right.$ vs. $\left.306 \times 10^{3} / \mu \mathrm{l}\right)$, but the difference was not significant $(p=0.153)$. Similarly, IL-6 was lower in this group of patients (10.3 vs. $12.8 \mathrm{pg} / \mathrm{ml})$; however, the difference was not significant $(p=0.717)$. Fifteen patients took acetylsalicylic acid on a regular basis. The mean platelet count in patients on acetylsalicylic acid was $293 \times 10^{3} / \mu$ l compared to $303 \times 10^{3} / \mu$ in patients without. The difference was not significant $(p=0.776)$. Similarly, the difference was not significant between the two groups (10.8 vs. $12.8 \mathrm{pg} / \mathrm{ml}$ ) regarding the IL-6 level $(p=0.748)$.

\section{Discussion}

There are an increasing number of observations that chronic inflammation promotes malignant transformation of cells and tissues [9]. The strong relationship between tumour and inflammation is also supported by the fact that the use of anti-inflammatory drugs helps to prevent the development of malignant diseases.

In tumour-related inflammation tissues are infiltrated by tumour-associated macrophages (TAMs), white blood cells, and inflammatory mediators such as tumor necrosis factor (TNF), IL-1, IL-6, and chemokines (CCL2 and CXCL8), which facilitates tissue remodelling and angiogenesis [10]. IL-6 is one of the most expressed inflammatory mediators in the microenvironment of the tumour. It takes part in the regulation of almost every process of tumour growth, such as the inhibi-
Table II. Correlation between tumour stage and mean platelet counts or IL-6 levels

\begin{tabular}{lccc} 
Parameter & Early stage & $\begin{array}{c}\text { Advanced } \\
\text { stage }\end{array}$ & P-value \\
\hline PLT average $\left[\times 10^{3} / \mu \mathrm{l}\right]$ & 294.33 & 310.98 & 0.434 \\
\hline IL-6 average $[\mathrm{pg} / \mathrm{ml}]$ & 5.4 & 16.2 & 0.0002
\end{tabular}

tion of apoptosis [11], facilitation of cell survival [12], proliferation [13], angiogenesis [14], tumour invasion and metastasis formation [15], and metabolism of tumour cells [16]. In the microenvironment of the tumour the main source of IL- 6 are the TAMs, the CD4+ T-cells, the myeloid-derived suppressor cells (MDSC), and the fibroblasts $[17,18]$. In the microenvironment of the tumour IL- 6 directly supports tumourigenesis with the modulation of intrinsic and extrinsic tumour cell activity [19]. IL-6 has a potential growth-stimulating effect in the tumour cells with the activation of several signalling pathways. IL- 6 stimulates tumour cell proliferation and survival with the activation of Ras/Raf/ MEK/MAPK, PI3K/AKT, and JAK/STAT pathways via the thyrosin phosphorylation of gp130 [13, 20]. In the inflammation transcriptional factors such as NF- $\kappa B$, STAT3 and primary inflammatory cytokines (IL-1b, IL-6 and TNF- $\alpha$ ) are essential [21]. NF- $\kappa B$ is the main regulator of the inflammation that emerges from control in several tumour types. IL- 6 is the main effector molecule in the NF- $\kappa$ B activation through the STAT- 3 pathway; IL- 6 is an important element of the NF- $\kappa B / I L-6 / S T A T-3$ cascade in tumourigenesis [12]. STAT-3 is necessary to keep NF- $\kappa B$ activated in tumours [22], while IL-6 promotes carcinogenesis with its proinflammatory and cell-proliferative effect $[23,24]$. IL-6-induced thrombocytosis is accompanied both with the mRNA expression of hepatic TPO and the increase of plasma TPO [25].

In several types of gastrointestinal cancer, elevated serum IL-6 was detected $[26,27]$. STAT-3-dependent tumourigenesis correlates with the local secretion of IL- 6 in colorectal cancer [12]. Additionally, IL-6 produced by M2 macrophages induces tumour development in ulcerative colitis [28]. Because the inflammation promotes gastrointestinal tumour growth and progression via the

Table III. Correlation of platelet counts and clinical parameters with multivariant linear regression analysis

\begin{tabular}{lccc} 
Parameter & Coefficient & 95\% Cl & P-value \\
\hline IL-6 [pg/ml] & -0.226 & $-0.927-0.476$ & 0.526 \\
\hline Haemoglobin $[\mathrm{g} / \mathrm{l}]$ & -2.213 & $-3.016--1.411$ & $<0.001$ \\
\hline White blood cell count [g/l] & 24.813 & $19.301-30.324$ & $<0.001$ \\
\hline Advanced stage & 19.958 & $-16.747-52.663$ & 0.308
\end{tabular}


activation of IL-6-mediated STAT-3 pathway, it may be assumed that there is a strong correlation between IL-6, inflammation, and tumour progression.

Elevated serum IL-6 correlates clinically with advanced tumour stage in a variety of cancers, which implies that the inhibition of IL-6 signalling may result in therapeutic benefit. In tumours that are characterised by IL-6 overproduction, the inhibition of IL- 6 signalling or the minimisation of serum IL- 6 could be a therapeutic strategy.

Since the publication of Stone et al. no other study has supported or disproved their theory in other tumours. Our study does not support the paracrine-mediated paraneoplastic pathway in gastrointestinal tumours, in contrast to ovarian cancer. Although, univariant analysis showed correlation between elevated platelet counts and serum IL-6, multivariant analysis did not support this relationship. If the correlation was evaluated in the specific tumour types, a moderately strong correlation was found in colon and oesophageal cancer. Serum IL- 6 was more elevated in more advanced disease, as described in the literature. The exact reason has not been elucidated yet. Thrombocytosis accompanying malignancies is often postulated as the result of anaemia. However, in our patient setting the ability of anaemia to cause reactive thrombocytosis could not be supported. Thrombocytosis showed significant correlation with white blood cell count instead of IL-6; therefore, it may be implied that inflammatory process influences both parameters.

The weakness of our study is that the study group was heterogenous and the subgroups were relatively small. Therefore, we think that a similar study on a larger group of patients is required to support our findings.

\section{Conflict of interest}

The authors declare no conflict of interest.

\section{References}

1. Baranyai Z, Josa V, Toth A, et al. Paraneoplastic thrombocytosis in gastrointestinal cancer. Platelets 2016; 27: 269-75.

2. Ishizuka M, Nagata $\mathrm{H}$, Takagi K, et al. Preoperative thrombocytosis is associated with survival after surgery for colorecta cancer. J Surg Oncol 2012; 106: 887-91.

3. Palumbo JS, Talmage KE, Massari JV, et al. Platelets and fibrin(ogen) increase metastatic potential by impeding natural killer cell-mediated elimination of tumor cells. Blood 2005; 105: $178-85$

4. Nieswandt B, Hafner M, Echtenacher B, et al. Lysis of tumor cells by natural killer cells in mice is impeded by platelets. Cancer Res 1999; 59: 1295-300.

5. Karpatkin S, Pearlstein E, Ambrogio C, et al. Role of adhesive proteins in platelet tumor interaction in vitro and metastasis formation in vivo. J Clin Invest 1988; 81: 1012-9.
6. Borsig L, Wong R, Feramisco J, et al. Heparin and cancer revisited: mechanistic connections involving platelets, P-selectin, carcinoma mucins, and tumor metastasis. Proc Natl Acad Sci USA 2001; 98: 3352-7.

7. Placke T, Kopp HG, Salih HR. Modulation of natural killer cell anti-tumor reactivity by platelets. J Innate Immun 2011; 3: 374-82.

8. Stone RL, Nick AM, McNeish IA, et al. Paraneoplastic thrombocytosis in ovarian cancer. N Engl J Med 2012; 366: 610-8.

9. Landskron G, De la Fuente $M$, Thuwajit P, et al. Chronic inflammation and cytokines in the tumor microenvironment. J Immunol Res 2014; 2014: 149185.

10. Colotta F, Allavena P, Sica A, et al. Cancer-related inflammation, the seventh hallmark of cancer: links to genetic instability. Carcinogenesis 2009; 30: 1073-81.

11. Lin MT, Juan CY, Chang KJ, et al. IL-6 inhibits apoptosis and retains oxidative DNA lesions in human gastric cancer AGS cells through up-regulation of anti-apoptotic gene mcl-1. Carcinogenesis 2001; 22: 1947-53.

12. Grivennikov S, Karin E, Terzic J, et al. IL-6 and Stat3 are required for survival of intestinal epithelial cells and development of colitis-associated cancer. Cancer Cell 2009; 15: 103-13.

13. Wegiel B, Bjartell A, Culig Z, et al. Interleukin-6 activates PI3K/ Akt pathway and regulates cyclin A1 to promote prostate cancer cell survival. Int J Cancer 2008; 122: 1521-9.

14. Wei LH, Kuo ML, Chen CA, et al. Interleukin-6 promotes cervical tumor growth by VEGF-dependent angiogenesis via a STAT3 pathway. Oncogene 2003; 22: 1517-27.

15. Oh K, Lee OY, Shon SY, et al. A mutual activation loop between breast cancer cells and myeloid-derived suppressor cells facilitates spontaneous metastasis through IL-6 trans-signaling in a murine model. Breast Cancer Res 2013; 15: R79.

16. Mauer J, Denson JL, Bruning JC. Versatile functions for IL-6 in metabolism and cancer. Trends Immunol 2015; 36: 92-101.

17. Nagasaki T, Hara M, Nakanishi H, et al. Interleukin-6 released by colon cancer-associated fibroblasts is critical for tumour angiogenesis: anti-interleukin-6 receptor antibody suppressed angiogenesis and inhibited tumour-stroma interaction. Br J Cancer 2014; 110: 469-78.

18. Nolen BM, Marks JR, Ta'san S, et al. Serum biomarker profiles and response to neoadjuvant chemotherapy for locally advanced breast cancer. Breast Cancer Res 2008; 10: R45.

19. Fisher DT, Appenheimer MM, Evans SS. The two faces of IL-6 in the tumor microenvironment. Semin Immunol 2014; 26: 38-47.

20. Leu CM, Wong FH, Chang C, et al. Interleukin-6 acts as an antiapoptotic factor in human esophageal carcinoma cells through the activation of both STAT3 and mitogen-activated protein kinase pathways. Oncogene 2003; 22: 7809-18.

21. Bromberg J, Wang TC. Inflammation and cancer: IL- 6 and STAT3 complete the link. Cancer Cell 2009; 15: 79-80.

22. Kesanakurti D, Chetty C, Rajasekhar Maddirela D, et al. Essential role of cooperative NF-kappaB and Stat3 recruitment to ICAM-1 intronic consensus elements in the regulation of radiation-induced invasion and migration in glioma. Oncogene 2013; 32: 5144-55.

23. Yeoh GC, Ernst M, Rose-John S, et al. Opposing roles of gp130-mediated STAT-3 and ERK-1/ 2 signaling in liver progenitor cell migration and proliferation. Hepatology 2007; 45: 486-94 
24. Johnson C, Han Y, Hughart N, et al. Interleukin-6 and its receptor, key players in hepatobiliary inflammation and cancer. Transl Gastrointest Cancer 2012; 1: 58-70.

25. Kaser A, Brandacher G, Steurer W, et al. Interleukin-6 stimulates thrombopoiesis through thrombopoietin: role in inflammatory thrombocytosis. Blood 2001; 98: 2720-5.

26. De Vita F, Romano C, Orditura $M$, et al. Interleukin-6 serum level correlates with survival in advanced gastrointestinal cancer patients but is not an independent prognostic indicator. J Interferon Cytokine Res 2001; 21: 45-52.

27. Waldner MJ, Foersch S, Neurath MF. Interleukin-6: a key regulator of colorectal cancer development. Int J Biol Sci 2012; 8: $1248-53$.

28. Schiechl G, Bauer B, Fuss I, et al. Tumor development in murine ulcerative colitis depends on MyD88 signaling of colonic F4/80+CD11b(high)Gr1(low) macrophages. J Clin Invest 2011; 121: $1692-708$.

Received: 23.03.2019

Accepted: 27.08 .2019 